1388 DIABETES, CARDIOVASCULAR DISEASE, PSYCHOSOCIAL DISTRESS AND OTHER RISKS AMONG AUSTRALIAN FARMERS AND AGRICULTURAL COMMUNITIES HEALTH SURVEILLANCE AND OUTCOMES

1,2Susan Brumby", 1,2Muhammad Aziz Rahman, ${ }^{3}$ Joe Lewis, ${ }^{3}$ Tracey Hatherell, ${ }^{3}$ Tam Phillips. 'Deakin University, School of Medicine, Waurn Ponds, Victoria, Australia; ${ }^{2}$ La Trobe University, School of Nursing and Midwifery, Melbourne, Victoria, Australia; ${ }^{3}$ Western District Health Service, National Centre for Farmer Health, Hamilton, Victoria, Australia

\subsection{6/oemed-2018-ICOHabstracts. 1324}

Background Farmers and rural populations have increased risk of cardiovascular disease, diabetes and suicide compared to general Australians. They also encounter problems of equitable access of expertise, exacerbated by large distances. If risk factors are identified or prevented then better health outcomes should follow for this high risk group. There is also a lack of cultural competence in health professionals around agricultural work, and its occupational and lifestyle risks.

Methods A cross-sectional study was conducted across rural Australia on 1697 participants during 2009-2016 at agricultural events to explore the behavioural, cardiovascular and diabetes risks among the farming community. Study participants were $>18$ years of age, spoke English and were involved/associated with farming. Diabetes risk was assessed by the validated AUSDRISK tool and cardiovascular risk through a 20 min one- on- one assessment - anthropometric measures, blood cholesterol, blood glucose, blood pressure, psychosocial distress, and waist measurement. Participants were provided with health information relevant to their risks and also recommended for further follow up.

Results Mean age was $53( \pm 15.5)$ years, 62\% was male and $58 \%$ were farmers/agricultural workers. More than two-thirds (73\%) were overweight/obese; no difference between farmers and non-farmers. Males were more likely to undertake short term risky alcohol use compared to females (62\% vs 46\%), although both were higher than Australian rates. 55\% were at risk of developing type 2 diabetes within 5 years; males $(90 \%$ vs $79 \%$, RR1.14, 95\% CI: 1.09 to 1.20$)$ and farmers (88\% vs $83 \%)$ were at increased risk. Hypertension $(\geq 140 / 90 \mathrm{mmHg})$ was $44 \%$ and more common in males and farmers.

In 2016, a random selection (150) were contacted to evaluate change in their behaviours and engagement with health practitioners since the intervention with surprising outcomes.

Conclusion Health surveillance and occupationally sensitive placed-based interventions for farming/rural populations should be the primary focus for health promotion strategies.

\section{SUSTAINABLE FARM FAMILIES ACROSS THE GLOBE- THE MOST IMPORTANT PART OF ANY FARM IS A HEALTHY FARM FAMILY}

\footnotetext{
1,2Susan Brumby*, ${ }^{2}$ Tracey Hatherell, ${ }^{3}$ Jordan Jensen, ${ }^{3}$ Laura Nelson. ${ }^{1}$ Deakin University, School of Medicine, Waurn Ponds, Victoria, Australia; ${ }^{2}$ Western District Health Service, Hamilton, Victoria, Australia; ${ }^{3}$ Farm Safety Centre, Raymond, Alberta, Canada
}

\subsection{6/oemed-2018-ICOHabstracts. 1325}

Background Farmers across the globe have increased risks accident, injury, cardiovascular disease, diabetes, suicide and zoonosis. They also face difficulties accessing expertise exacerbated by large distances and lack of transport. The Sustainable Farm Families (SFF) program commenced in Australia in 2003 and has delivered 151 programs to over 2500 Australian farm men and women. In 2014, SFF commenced in Alberta, Canada and over 400 farmers have participated including 17 Hutterite communities. Each SFF program consists of 3 workshops, over 4 days, approximately 6-12 months apart. Methods SFF is a multifaceted health program, developed specifically for the agricultural context. Each workshop is facilitated by trained SFF nurses and an agricultural facilitator. At the beginning of each workshop a full health assessment is gathered-anthropometric measures, lipid studies, glucose, blood pressure, psychosocial distress, waist measurement and $\%$ body fat. Health and safety behaviours are also reviewed. Education sessions on CVD, diabetes, stress, farm safety, anxiety, depression, diet and nutrition, respiratory conditions, pesticides, physical activity, men's health and women's health are devliered. Participants were $>18$ years, spoke English and were farming. Diabetes risk was assessed by the validated AUSDRISK or CANRISK tool and psychosocial distress using the Kessler K10.

Results More men than women participated showing that farmers are interested in their health, wellbeing and safety. 'Can't take care of the farm if you don't take care of yourself.' This presentation will discuss the baseline results from Australia and Canada. Where longitudinal data is available it will be discussed. In Australia, the results showed that the more risk factors you had when you began the SFF program the better you did, including reducing your risk factors.

Conclusion Both the Australian and Canadian program have been positively and extensively independently evaluated. The SFF program has been successfully repeated and transferred to Alberta, Canada, saving lives and saving money across the globe.

\section{PRELIMINARY STUDY OF PESTICIDES USE CONDITIONS IN CASHEW PRODUCTION IN CÔTE D'IVOIRE}

${ }^{1,2} \mathrm{JH}$ Kouadio*, ${ }^{1}$ YS Koffi, ${ }^{2} \mathrm{~B}-\mathrm{Y}$ Yeboué-Kouamé, ${ }^{1} \mathrm{KC}$ Diby, ${ }^{2} \mathrm{AJ}$ Eba. ${ }^{1}$ Equipe de recherche Gestion de la Qualité des Productions végétales (GQPV), Département de Biochimie Microbiologie, UFR Agroforesterie, Université Jean Lorougnon Guédé, B.P: 150 Daloa; ${ }^{2}$ Laboratoire de (Bio) Toxicologie et Hygiène Industrielle, DPPSST, CNPS 01 B.P. 317 Abidjan, Côte d'Ivoire

\subsection{6/oemed-2018-ICOHabstracts. 1326}

Introduction Côte d'Ivoire is the top exporter as well as producer of cashew nuts in the world. Chemical pesticides are used as one of preference crop protection measures. However, the conditions use of any pesticide must meet good agricultural practices in order to mitigate occupational risks for pesticides users, to ensure cashew nuts safety and other hand the preservation of the ecosystem. Our study explored essentially occupational risks linked to chemical pesticides in cashew farming and the rate of non-homologated products use in Côte d'Ivoire.

Methods Data collection was through well-structured questionnaire administered on respondents selected through random sampling technique. The geographical site of our study was two main cashew production areas namely the Gbeke, Centre (6 departments) and the Poro, North (4 departments) of Côte d'Ivoire. In total, 43 farmers have participated in the study covering the whole of the 10 departments of the two regions. After counting of survey sheets, data have been codified, entered and analysed using the software Sphinx 4.5.0.30. 